\title{
THE EFFECT OF IRRIGATION WITH MAGNETICALLY TREATED WATER ON THE TRANSLOCATION OF MINERALS IN THE SOIL
}

\author{
RAMI NORAN ${ }^{\star}$, URI SHANI* AND ISRAEL LIN ${ }^{\dagger}$ \\ ${ }^{\star}$ The Institute of Evolution, University of Haifa, Haifa 32199, Israel \\ *"Aravah" Research Station, Yotvata, Mobile Post Office, Ayaloth District \\ 88820 , Israel \\ $\dagger_{\text {Department of Mineral Engineering, Technion, Haifa 32000, Israel }}$
}

(Received October 11, 1995, accepted November 13, 1995)

\begin{abstract}
Magnetically treated water (MTW) is water passed through a magnetic field before being used. Applications of MTW are abundant in industry where it is used to prevent scaling on inner walls of pipes conveying fluids, especially water. In recent years scientists investigating the subject have concluded that the magnetic field interacts with the surface charges of particles in the fluid solutions affecting the crystallisation and precipitation of the solids in them. These processes are of significant effect on the translocation of minerals in irrigated soil.

In this work the concentrations of $\mathrm{K}, \mathrm{N}, \mathrm{P}, \mathrm{Na}$ and $\mathrm{Ca}+\mathrm{Mg}$, as well as the total mineral content in the MTW-irrigated soil were compared with the same data in soil irrigated with ordinary water. The soil was sampled at three different locations at three different distances from the dripper line, representing three different leaching states of the soil. Differences in concentrations were found in at least one of the three locations with respect to each mineral and including the total mineral content. Most of the differences appeared in the less leached parts of the soil, in the bed margin. It appears that there is a general tendency of minerals to precipitate out of the solution faster in MTW conditions.
\end{abstract}

\section{INTRODUCTION}

For many years now research has been carried out on showing the effects of magnetic fields on growth processes and the development of plant tissues (Tolomei 
[1], Ssawastin [2], Audus [3], Dubinskaya [4], Pittman et al. [5], Dayal and Singh [6]). Such research, as a rule, involved exposure of the entire plant to an external magnetic field (Sheppard and Eizenbud [7], McLeod et al. [8]), induction of the magnetic field in the soil surrounding the root system of the plants (Vodianitskii [9], Vodianitskii and Lunkova [10]), or irrigation with.water that had undergone magnetic treatment before being introduced into the soil (Volkonskii et al. [11], Lin and Yotvat [12], Moran et al. [13, 14]).

Magnetically treated water (MTW) is the water subjected to treatment in and by a magnetic field. For irrigation purposes this means the water that had passed through an apparatus containing a permanent magnet. The use of MTW is common in various branches of industry as a precaution against accumulation of scale in the water supply system, in cooling towers and in thermal and solar heating installations (Lin and Yotvat $[12,15]$ ).

Much work has been done in this connection dealing with such minerals as calcium carbonate, phosphorus carbonate, barium sulphate, zinc phosphate and calcium oxalate. For instance, laboratory tests carried out in a certain heating system fed with MTW established that a deposit of $0.1 \mathrm{~g}$ of calcium carbonate had formed, as compared with $40 \mathrm{~g}$ accumulated in a system using untreated water. Tests conducted in five different humidity maintenance systems showed that the treatment prolonged their service life from 1000 to 1500 hours to over 2200 hours, the observation being called off after that (Donaldson [16]).

There is another system for magnetic water treatment which does not involve the use of an external magnetic field. Water is made to flow through a maze made of a proprietary alloy (Institute of Technology, Haifa 3200, Israel ๑) apparatus that is called the catalytic alloy conditioner. Principles of its operation were discussed by Kim [17].

In work done in recent years at the Department of Chemistry, Brunel University, London, UK, and dealing with the effects of the magnetic field on liquids, scientists came to a conclusion that the principal activity consists of the interaction between the magnetic field and the surface charges of particles in the liquid. According to these findings, the field can react with a wide variety of particles: ions, polar molecules, ion pairs, free radicals, crystalline crystallisation nuclei and suspensions with a surface charge. 
There are two kinds of reaction:

(1) Direct reactions with the charged particles, and

(2) Magneto-kinetic modifications (influence of the magnetic field on certain energy levels of the molecule).

As a result of these reactions the behaviour of the particles changes in the area of crystallisation and precipitation of the solutes in the solvent. The changes taking place were measured in a number of respect: the size of the crystallising particles, their shape, quantitative relationships between different crystalline shapes,crystallisation processes, the solubility of minerals, and the rate of precipitation.

In all these respects the influence of the magnetic treatment of the liquid was revealed, and as a result of these findings the main research effort is now focused on the study of modifications of the crystallisation processes and various scientific and commercial aspects connected therewith [16].

The mechanism of the MTW activity in the soil is as yet unclear. There is a possibility that the effect is physical, viz. through a change in the solvent capacity of the water. An increase in that capacity can be the explanation of the differences detected while examining the soluble fraction of the soil, between the ordinary water and MTW. These differences varied between 50 per cent to 300 per cent [18]. There is a conjecture that the water has a direct effect on physiological processes in the plant cells, and it is possible that the reactions of the plant are of secondary importance. The direct influence is concentrate mainly on the composition or the mineral structure of the soil.

The movement of the water during drip irrigation causes a "wet spot" on the soil surface on both sides of the dripper line. The salt concentrations in the soil change as a result of the salts being dissolved and washed away by the irrigation water. The movement of the salts in the soil corresponds to the route of progress of the wetting front of the water. This movement starts at the dripper line which is situated at the centre of the bed, and ends at the borderline of the wet spot on both sides of the line.

The direction of the movement is perpendicular to that of the line. At the end of irrigation, the wetting profile in the soil assumes the shape the shape of an onion 
(the "wetting onion") the salt content of which being so divided that the lowest concentration is found next to the dripper and the highest near the borderline of the wet spot [19].

The aim of the present work was to clarify the influence of the magnetic treatment of water on the movement of the salts in the field drip-irrigated with MTW and to determine if the distribution profile of the minerals dissolved in the MTW-irrigated area differs from that in the control area which was irrigated with the untreated water.

\section{MATERIALS AND METHODS}

\section{Location}

The investigation was carried out on an experimental plot of land which formed part of a field of fall melons grown organically at Kibutz Yotvata. The area had not been worked for three years before the experiment.

\section{Leaching the Soil}

The melon field containing the experimental plot was regularly irrigated, evaporation coefficient of 1.0 being taken into account. A dripper line dispensing $2.3 \ell / h$ per dripper and with drippers spaced at intervals of $40 \mathrm{~cm}$ was laid along the centre line of each bed in a groove 5 to $8 \mathrm{~cm}$ deep.

One week after the beginning of irrigation, the magnetic treatment of the irrigation water was started on plots assigned to such treatment. The treated and the control beds were adjacent to each other and located in close proximity to the outlet valve.

\section{Magnetically Treated Water}

The magnetic treatment was administered by passing the irrigation water through a metal pipe containing a magnetic apparatus called "Arimag" made by Elir, recommended to operate at throughput of $0.9 \mathrm{~m}^{3} / \mathrm{h}$. The magnetic treatment apparatus was set up close to the water outlet of the main line. 


\section{Fertilisation}

The experiment was operationally connected to the organic melon plot, and no mineral fertiliser was added. A guano solution of varying concentration was occasionally applied.

\section{$\underline{\text { Soil Wetness }}$}

The "wet spot", the boundary of the soil wetness as discernible by visual inspection of the soil surface, attained $50 \mathrm{~cm}$ on either side of the dripper. Examinations made at two-week intervals established that the amounts of water supplied by the two dripper lines were equal. One week before the end of the experiment the water content of the soil was measured, repeated four times, at a distance of $50 \mathrm{~cm}$ from the dripper, and depth of $30 \mathrm{~cm}$. The results were not significantly different: $86.5 \pm-.3$ per cent humidity in the MTW plot, against 85.8 \pm 1.0 per cent in the control plot.

\section{Soil Sampling for Testing Mineral Concentration}

In drip irrigation, the water movement and mineral leaching profile in the soil is in the shape of a half-ellipse, or "onion" [20, 21, 19]. The salt content of the "wetting onion" is so disturbed that the lowest concentration is found near the dripper, the highest on the "wet spot" boundary [19].

\section{$\underline{\text { Soil. Sampling Points }}$}

The range of the "wet spot" spread changed somewhat from one day to the next, due to temporary factors affecting evaporation, such as temperature, wind and insulation, or because of minute changes in the quantity of the water supplied. The border line of the wet spot as seen on the ground lies between the more distant ranges of expansion and the closer ones of the daily irrigation "onions".

Accordingly, sampling points were set at three distances, as shown in Fig. 1:
(A) inside the wet spot, close to the dripper line;
(B) inside the wet spot, close to its boundary;
(C) outside the wet spot, but close to its boundary. 
(C)

(B)

(A)

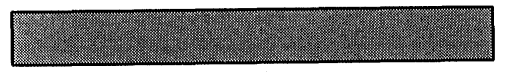

(A)

(B)

(C)

\section{Water front}

\section{Drip line}

Water front

Fig. 1 Schematic representation of the experimental plot. The diagram shows locations of the samplings (A), (B) and (C), in distances of 5,40 and $60 \mathrm{~cm}$, respectively, from the dripper line. The boundary of the wet spot (the wetting front) is $50 \mathrm{~cm}$ from the line.

It is important to stress that while point (A) is in the area most highly leached of minerals, points (B) and (C) are in the area where the minerals settle. In other words, the area of higher concentration of the leached minerals [19]. By means of points (A), (B) and (C) in Fig. 1, these two different areas can be defined in terms of the extent of leaching they have undergone:

1. Area (A-B) (Between (A) and (B)) was the most highly leached because the water passed through it and the wetting front moved across it throughout all the irrigation cycles.

2. Area (B-C) (Between (B) and (C)) was less leached than the above because the water passed through it and the wetting front moved across it for only part of the irrigation cycles. 
Soil Sampling.

Soil specimens were taken after 28 days of irrigation with MTW. The sampling, from a depth of $20 \mathrm{~cm}$, was repeated four times at a distance of from $8 \mathrm{~m}$ to $10 \mathrm{~m}$ from the end of the plot. The specimens, in paper bags, were dried in a ventilated storeroom and then taken to the Field Service Laboratory at Hadera.

Statistics.

The confidence level of the differences in the results was examined by the $t$-test.

\section{RESULTS}

The Difference in Salt Concentrations Between the MTW-Irrigated and Control Plots

The boundary of the "wet spot" was $50 \mathrm{~cm}$ distant from the dripper line. Soil samples were taken at points (A), (B) and (C) after 28 days of irrigation in order to measure the overall concentration of solutes and the concentrations of the salts of $\mathrm{K}, \mathrm{P}, \mathrm{N}, \mathrm{Na}$ and $\mathrm{Ca}+\mathrm{Mg}$, at different distances from the dripper line (see Fig. 1 and section Materials and Methods). The differences observed between the MTW-irrigated and the control beds reached, at certain points, a confidence level of between 90 per cent to 99 per cent (Table 1).

\section{Concentrations Next to the Dripper Line}

The mineral concentrations in the soil close to the dripper line as listed in Table 1 are illustrated in Figure 2. Near the line the soil is leached to a higher degree than elsewhere within the confines of the "wetting onion" [19], and clear differences in salt concentrations between the MTW-irrigated and the control beds were found only with respect to the divalent ions and phosphorus (Figure 2 and Table 1).

\section{Translocation of Salts in Two Different Leaching Areas}

(For definitions of the zones, see Section "Materials and Methods". 
Table 1 Electrical conductance and mineral concentrations in the soil solutions at different distances from the dripper line (Average and standard deviation of four repeats of each test).

\begin{tabular}{||c|c|c|c|c|c|c|}
\hline \multirow{3}{*}{ Parameter } & \multicolumn{6}{c|}{ Distance from dripper line } \\
\cline { 2 - 7 } & \multicolumn{2}{|c|}{$(\mathrm{A})$} & \multicolumn{2}{c|}{ (B) } & \multicolumn{2}{c|}{ (C) } \\
\cline { 2 - 7 } & \multicolumn{2}{|c|}{$5 \mathrm{~cm}$} & \multicolumn{2}{c|}{$40 \mathrm{~cm}$} & \multicolumn{2}{c|}{$60 \mathrm{~cm}$} \\
\cline { 2 - 7 } & Control & $\mathrm{MTW}$ & Control & MTW & Control & MTW \\
\hline EC & 4.3 & 4.7 & 9.9 & $10.9 \mathrm{a}$ & 10.1 & $8.3 \mathrm{c}$ \\
{$[\mathrm{mmho} / \mathrm{cm}]$} & 0.5 & 0.5 & 0.3 & 0.3 & 1.8 & 1.0 \\
\hline $\mathrm{Na}[\mathrm{Meq} / 1]$ & 16.6 & 16.9 & 45.0 & $53.3 \mathrm{a}$ & 49.5 & 39.8 \\
& 1.9 & 1.9 & 3.0 & 2.1 & 12.8 & 7.3 \\
\hline $\mathrm{Ca}+\mathrm{Mg}$ & 39.6 & $56.4 \mathrm{a}$ & 73.0 & 74.4 & 92.2 & $62.7 \mathrm{~b}$ \\
{$[\mathrm{Meq} / \mathrm{l}]$} & 6.8 & 6.3 & 14.9 & 19.1 & 12.6 & 14.2 \\
\hline $\mathrm{K}[\mathrm{Meq} / \mathrm{l}]$ & 1.3 & 1.3 & 12.0 & 9.7 & 5.6 & $8.4 \mathrm{c}$ \\
& 0.1 & 0.1 & 0.5 & 1.9 & 0.8 & 2.5 \\
\hline $\mathrm{N}\left[\mathrm{NO}{ }_{3}\right]$ & 3.6 & 4.0 & 8.4 & $15.3 \mathrm{~b}$ & 19.5 & 13.8 \\
{$[\mathrm{ppm}]$} & 1.1 & 0.5 & 1.3 & 5.2 & 6.5 & 7.6 \\
\hline $\mathrm{P}(\mathrm{Olsen})$ & 118.9 & $239.0 \mathrm{a}$ & 123.3 & $195.8 \mathrm{~b}$ & 71.1 & 117.3 \\
{$[\mathrm{ppm}]$} & 13.9 & 17.4 & 51.5 & 28.4 & 29.0 & 26.5 \\
\hline \hline
\end{tabular}

$$
\begin{aligned}
& a-\quad p<0.01 \\
& b-0.01<p<0.05 \\
& c-0.05<p<0.10
\end{aligned}
$$

\section{The Completely Leached Zone}

Between points (A) and (B) which define the A-B zone, a fall in concentrations typical of the "wetting onion" [19] is observed, with no significant difference between the MTW-irrigated and the control beds (Table 1).

\section{The Partially Leached Zone B-C}

The translocation of salts in the less leached $(B-C)$ zone is shown in Figure 3 , prepared based on data in Table 1 . As distinct from the A-B zones, there are differences between the B-C zones of the two plots: in the one irrigated with MTW a common and characteristic profile indicates a drop in salt concentrations from point $\mathrm{B}$ to point $\mathrm{C}$ (Figure $3 \mathrm{~b}$ ), whereas in the control 


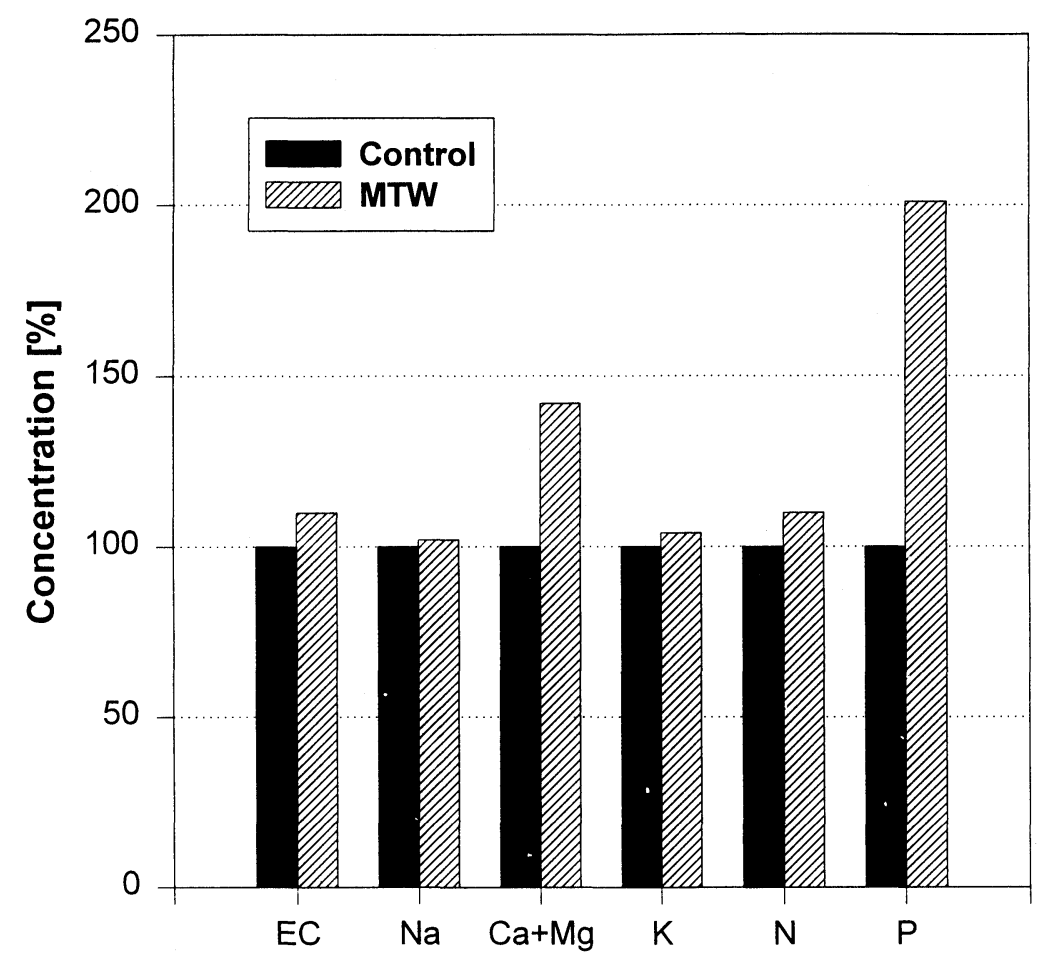

Fig. 2 Concentration of salts in the soil at sampling location (A), the outlet of the irrigation water from the dripper (the centre of the "wetting onion"), according to the data in Table 1, column A (see also Fig. 1). No difference was found between the MTW-irrigated plot and control, as regards both overall electrical conductivity and the specific concentrations of $\mathrm{N}, \mathrm{K}$ and $\mathrm{Na}$. Only the results with respect to $\mathrm{P}$ and $\mathrm{Ca}+\mathrm{mg}$ differ in this connection.

beds there is no common and characteristic profile (with regard to some of the salts there is a tendency to a rise in salt concentrations from point $\mathrm{B}$ to point C (Figure 3a). 

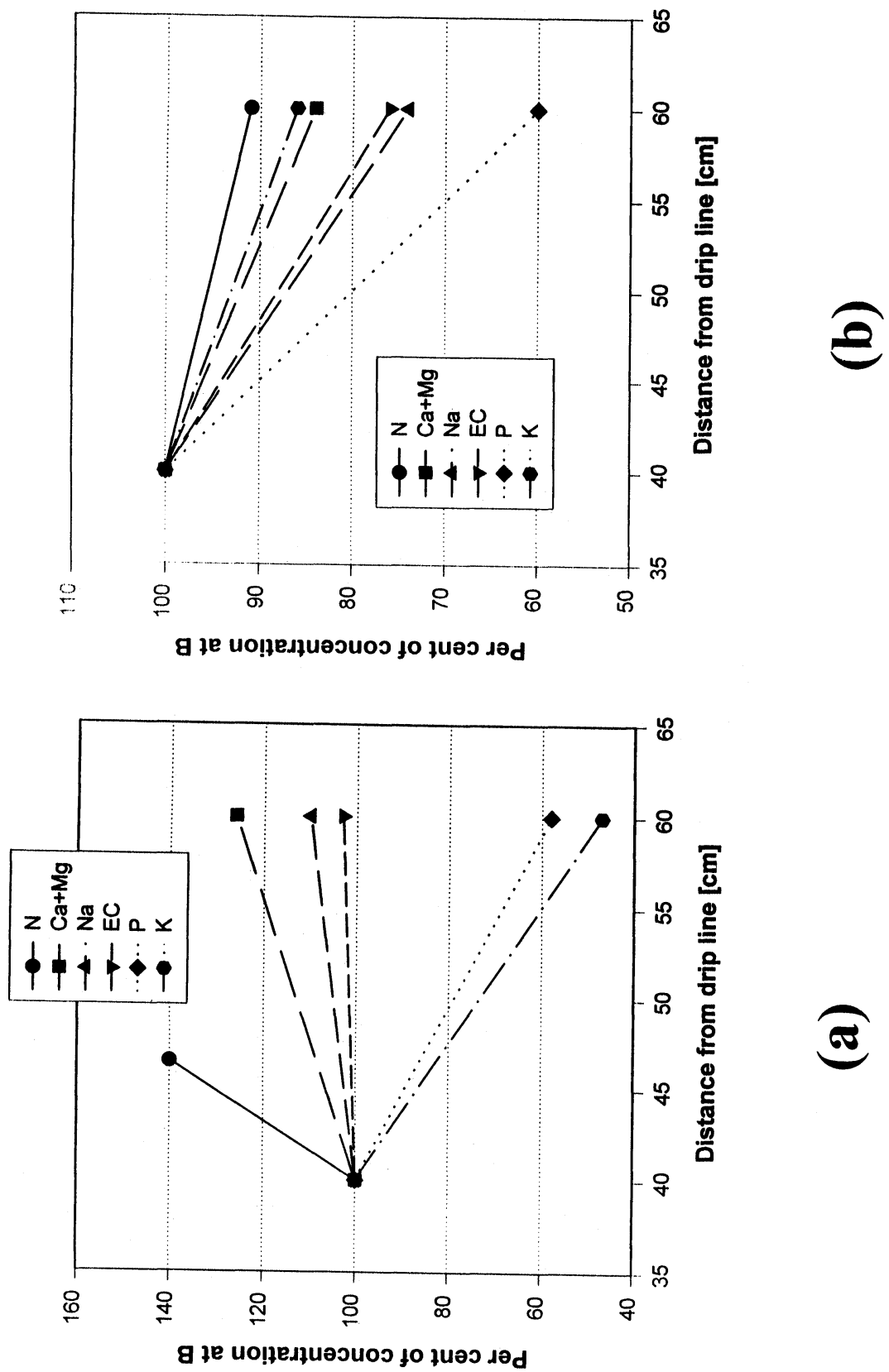

Fig. 3 The change in salt concentrations in the soil in the partially leaching area $(\mathrm{B}-\mathrm{C})$, at different distances from the dripper. The results are quoted as percentages of the concentration at point (B). 3a: untreated water, $3 \mathrm{~b}$ : magnetically treated water. 


\section{DISCUSSION}

The aim of this work was to elucidate the influence of magnetic water treatment on the movement of salts in the soil. During drip irrigation the movement of the water perpendicularly to the dripper line causes a "wet spot" on the soil surface on both sides of the line [19]. Acting on the assumption that the magnetic field affects the particles in the solution [16], the possibility was investigated that the field alters the interaction of the solutes with the water and the soil, and as a result the concentrations of the minerals in the soil of the plot irrigated with magnetically treated water at given distances from the dripper line differ from those in the control plot.

The Differences in the Salt Concentrations Between the MTW-Irradiated and Control Plots

The examination of the overall solute concentrations and the concentrations of specific salts (potassium, phosphorus, nitrogen, sodium and calcium + magnesium) produced results that support the basic assumption that irrigation with MTW affects the movements of salts in the soil. With respect to all salts and at different distances from the dripper line, differences were found between the MTW-irrigated and the control plots, at confidence levels of between 90 and 99 per cent (Table 1).

The Influence of the MTW-Irrigation on the Movement of Salts in the Soil in Area B-C

In area $\mathrm{B}-\mathrm{C}$ the analysis of the movement of salts in the soil within the limits of the "wet spot" showed clear differences between the MTW-treated and control plots (Fig. 1). In the former, there is a common and characteristic profile showing a reduction in the salt concentration from the point inside the "wet spot" to the point outside (Fig. 3b), whereas in the control plot there is no such common and characteristic profile.

Moreover, an opposite tendency is discernible in some of the salts, viz. a tendency to a rise in the salt concentration from the point within to that outside the "wet spot" (Fig. 3a). The fact that the differences were found in the B-C area (Fig. 1, 
the area subjected to partial leaching), and not in the completely leached area A-B can be explained by the latter area's salt leaching having reached the highest, final stage, both on the MTW-irradiated and control plots. At that stage, it is already difficult to detect any differences.

\section{Calcium and Magnesium Salts}

Close to the dripper line (at point A) there is a noticeably higher concentration of the divalent ions $(\mathrm{Ca}+\mathrm{Mg})$, in plots irrigated with MTW, as compared with the control plots (Fig. 2). This result fits in well with the known phenomenon of the effect of MTW on the prevention of the calcium salt accumulation ("scale") in pipes of industrial systems. This phenomenon is explained by the fact that the passage of the water through a magnetic and similar apparatus causes calcium salts to create, under the influence of the said treatment, relatively large crystals. These crystals sink easily compared with slow crystallisation and precipitation of these salts in untreated water [17].

The Changes in Phosphorus Concentration in the Soil

Already in close proximity of the dripper line, great difference in the concentrations of this mineral in the MTW-irrigated and control plots is evident (Table 1, Fig. 2). The data point to a particularly high solubility of phosphate under the influence of the magnetic treatment, conforming to the findings of work carried out in connection with zinc phosphate at the Brunel University. Experiments run in the laboratory, and data supplied by industry, showed clear influence of the magnetic treatment on the increase in solubility (or in the level of concentration in supersaturation) of zinc phosphate. As regards calcium phosphate, they shown an increase of 50 per cent in the dissolution capacity after 24 hours of magnetic treatment, and five-fold increase after 120 hours [16].

\section{CONCLUSIONS}

The results of this work confirm the assumption that as a result of the influence of the magnetic field on solutes [16], the interaction between soil particles and salts 
dissolved in ordinary water does not resemble the interaction between the soil particles and the salts dissolved in magnetically treated water. It appears that, generally speaking, magnetic treatment of water slows down the movement of minerals. It occurs probably due to the effect of acceleration of the crystallisation and precipitation processes of the solute minerals as a result of magnetic treatment. The effect is clearly discernible when the flushing is not complete (Figure 3).

What is still required is an investigation of the kinetics of the mineral movement in the soil during irrigation, in order to study the dependence of the distribution profile of different minerals on the quantity of water introduced into the soil. It is worthwhile to clarify the specific effect of irrigation with magnetically treated water on each mineral separately.

The results obtained in the present work with respect to phosphorus, and other works showing the effect of the magnetic field on the solubility of the phosphorus salts [16], are an indication of the interest that is attached to the study of the phosphate behaviour in MTW-irrigated soil.

\section{REFERENCES}

[1] G. Tolomei: Azione del magnetizmo sulla germinazione. Malpighia 7 (1893), 470

[2] P.W. Ssawastin: Magnetic growth reactions in plants. Planta 12 (1930), 327

[3] L.J. Audus: Magnetotropism: A new plant-growth response. Nature 185 (1960), 132-134

[4] D.A. Dubinskaya: The effect of a constant magnetic field on growth of maize seedlings. Fiziol. rast. 20 (1973), 183-186

[5] U.J. Pittman et al.: Effect of magnetic seed treatment on amylolytic activity of quiescent and germinating barley and wheat seeds. Canad. J. Plant Sci. 59/4 (1979), 1007-1011

[6] S. Dayal and R.P. Singh: Effect of seed exposure to magnetic field on the height of tomato plant. Indian J. Agricult. Sci. 56 (1986), 483-486

[7] A.R. Sheppard and M. Eizenbud: Biological effects of electric and magnetic fields of extremely low frequency. New York University Press, New York 1977 
[8] B.R. McLeod et al.: Plants grow better in magnetic fields. Research and Development Outlays 45 (1992)

[9] Yu. N. Vodianitskii: Ferromagnetic soil-ameliorating materials. Zemledelie 9 (1974), 86-88

[10] Yu. N. Vodnianitskii and V.N. Lunkova: The effect of the ferromagnetic improvement of the soil on the availability of nutrients to plants and on the crop yield. Khim. Sel'sk. Khoz. 14/7 (1976), 21-23

[11] N.A. Volkonskii et al.: Effect on plants of soil water following its magnetohydrodynamic treatment. Vestn. Skh. Nauki (Moscow) 7 (1978), 93-96

[12] I.J. Lin and J. Yotvat: Exposure of irrigation and drinking water to a magnetic field with controlled power and direction. J. Magn. Magn. Mater. 83 (1990), 525-526

[13] R. Moran et al.: Irrigation of organically grown melons with water exposed to magnetic treatment. Magnets 6/7 (1992), 5-10

[14] R. Moran et al.: The effect of magnetic treated irrigation water on the development of pepper and melon crops in sterilized soil (in Hebrew). Hassadeh 74/3 (1993), 268

[15] I.J. Lin and J. Yotvat: Electromagnetic treatment of drinking and irrigation water. Water \& Irrigation Rev. 8/4 (1988), 16-18

[16] J.D. Donaldson: Magnetic treatment of fluids. Report on a lecture presented at the BVPW symposium in the Frankfurt Airport Conference centre (1990), $1-12$

[17] L. Kim: Catalytic water conditioning. Water Cond. Purif. Mag., February $1987,72-78$

[18] M. Harari and I.J. Lin: The effect of irrigation water exposed to magnetic treatment on the growth of sugar melons (cantaloupes) and tomatoes for industry. Magnets 5/11 (1991), 4-15

[19] E. Bresler: Two-dimensional transport of solutes during non-steady infiltration from a trickle source. Soil Sci. Soc. Amer. Proc. 39 (1975), $604-611$

[20] S. Mostaghimi and K. Mitchell: Pulsed trickling effects on soil moisture distribution. Water Res. Bul.19 (1983), 605-612

Keywords: magnet, irrigation, water treatment, soil 